\title{
Sexual violence, mood disorders and suicide risk: a population-based study
}

\author{
Violência sexual, transtornos de humor e risco de suicídio: \\ um estudo de base populacional
}

\author{
Thaíse Campos Mondin ${ }^{1}$ \\ Taiane de Azevedo Cardoso ${ }^{1}$ \\ Karen Jansen ${ }^{1}$ \\ Caroline Elizabeth Konradt ${ }^{1}$ \\ Rosana Ferrazza Zaltron ${ }^{1}$ \\ Monalisa de Oliveira Behenck ${ }^{1}$ \\ Luciano Dias de Mattos ${ }^{1}$ \\ Ricardo Azevedo da Silva ${ }^{1}$
}

${ }^{1}$ Programa de PósGraduação em Saúde e Comportamento, Universidade Católica de Pelotas. R. Félix da Cunha 412, Centro. 96015-560 Pelotas RS Brasil.karenjansen315@ hotmail.com

\begin{abstract}
This article seeks to analyze the association between sexual violence, manic and depressive episodes, and suicide risk among young adults. This is a cross-sectional population-based study carried out with young people between 18 and 24 years of age in a town in southern Bra$z i l$. The sample was selected through clusters. The prevalence of sexual violence, manic, depressive and mixed episodes and suicide risk were evaluated, as well as the association between them. The chi-square test and Poisson regression were used for statistical analysis. The study sample comprised 1,560 subjects. Among these, 3.1\% had suffered sexual violence at some point in their life. The prevalence of depressive, mixed episodes, and (hypo)manic episodes were 10\%, 2.4\% and 2.3\%, respectively. Suicide risk had a prevalence of $8.6 \%$ in the total sample. Young people who have suffered sexual violence are more likely to be subject to mood changes or suicide risk than those who have not $(p<0.05)$, except for the occurrence of (hypo)manic episodes. These results revealed a strong association between sexual violence and depressive and mixed episodes and suicide risk.
\end{abstract}

Key words Sexual violence, Sexual abuse, Mood disorders, Depression
Resumo $O$ artigo tem por objetivo analisar a associação entre abuso sexual, episódios maníacos, depressivos e risco de suicídio em jovens adultos. Este é um estudo transversal de base populacional realizado com jovens entre 18 e 24 anos em $\mathrm{Pe}$ lotas/RS. A seleção da amostra foi realizada por conglomerados. Foram avaliados a prevalência de violência sexual, o episódio de mania, depressão, misto e o risco de suicídio. Para a análise bruta dos dados foi utilizado o teste Qui-Quadrado, posteriormente, a análise ajustada foi realizada por Regressão de Poisson. A amostra do estudo foi de 1560 jovens, dos quais 3,1\% haviam sofrido abuso sexual em algum momento de sua vida. $O$ episódio depressivo esteve presente em 10,0\% dos jovens entrevistados, seguido pelo maníaco (hipo) (2,3\%) e pelo misto (2,4\%). O risco de suicídio apresentou prevalência de 8,6\% na amostra total. Nos jovens que sofreram abuso sexual, a probabilidade de apresentar alterações de humor ou risco de suicídio foi maior do que naqueles que não haviam sofrido $(p<0,05)$, exceto para a ocorrência de episódio maníaco (hipo). Os achados deste estudo indicam uma forte associação entre abuso sexual e episódios de depressão, misto e risco de suicídio, ainda, em uma amostra sem nenhum tratamento.

Palavras-chave Abuso sexual, Depressão, Depressão bipolar, Risco de suicídio 


\section{Introduction}

Sexual assault has been recognized as a serious public health and social problem, resulting not only in great physical and psychological impact, but also in behavioral problems to the victims ${ }^{1-5}$. Despite the low percentage of complaints, sexual assault has been increasing. According to the World Health Organization [WHO] 20\% of women and from $5 \%$ to $10 \%$ of men reported suffering sexual violence and the overall prevalence of rape was $2-5 \%$.

Some studies focus on the association between sexual abuse, unipolar depression and bipolar disorder ${ }^{7,8}$. A current study carried out in Canada, verified that sexual abuse was associated with several mental disorders but not with bipolar disorders9. In another study which was analyzed 269 patients who had experienced sexual violence found that $48.7 \%$ were diagnosed with some affective disorder and $22.3 \%$ had at least one suicide attempt in the past ${ }^{10}$. Depression in later life represents the main psychopathological manifestation associated with traumatic events in childhood. Researchers observed that sexual abuse in children was a primary risk factor for the onset of bipolar disorder ${ }^{11}$.

Individuals who suffered some type of violence, such as sexual abuse, rape, physical violence or harassment, are more likely to suffer from other forms of violence throughout their $\operatorname{lives}^{12}$. The association between sexual violence and subsequent mental disorders is already well established, however, there are still controversies about the relationship between sexual violence and bipolar disorder.

Especially in Brazil, we know little about the different effects associated with sexual violence. Therefore, population studies are important to examine sexual violence prevalence and thus contribute to political actions, linked to prevention of sexual violence and mood disorders, as well as, strategies of intervention. Yet this type of study is less likely to bias since it is a population that is not seeking treatment.

Considering the probable relationship between sexual assault and mood disorders, this study aimed to analyze the association between self-reported sexual violence and (hypo) mania, depressive and mixed episodes as well as the suicide risk in a sample of young adults aged 18 and 24 years.

\section{Materials and methods}

A cross-sectional population-based study was carried out with young adults between the ages of 18 and 24 years, living in the urban area of the city of Pelotas, Brazil. The sample collection was performed by clusters from August 2007 to December 2008 considering the population of 39667 young adults and according to the current census of 448 sectors in the city of Pelotas. In order to guarantee the necessary sample size, 89 census-based sectors were randomly selected. A systematic sampling technique was employed for recruitment. Out of the 1762 recruited subjects, $11.6 \%$ refused to participate. Thus, 1560 subjects were interviewed ${ }^{13}$.

The study included seven interviewers, psychology and physiotherapy undergraduate students from the Universidade Católica de Pelotas. To implement the instruments interviewers were trained by psychologists with extensive application experience and weekly meetings were conducted during all data collection period.

We documented information regarding demographic, education of young and head of household and parent's marital status by self-reported. Socioeconomic status was assessed using a classification proposed by the Brazilian Association of Research Companies (Associação Brasileira de Empresas de Pesquisa, ABEP $)^{14}$. This classification is based on the accumulation of material goods and also on the schooling of the head of the household and it places the subjects into economic classes (A, B, C, D, or E according to the scores obtained; " $\mathrm{A}$ " refers to the highest socio-economic class and " $\mathrm{E}$ " the lowest.

In the present paper, sexual violence was considered as the sexual assault. The sexual violence was assessed by a self-administered question: Have you ever been physically forced to have sexual intercourse?. Current mood disorders and suicide risk were assessed using the Mini International Neuropsychiatric Interview 5.0 (MINI), which is a short structured diagnostic interview widely used by clinicians and in research based on DSM-IV and CID-10 criteria. The MINI is divided into modules identified by letters corresponding to diagnostic categories. Among these categories, it includes the evaluation of depressive, manic and hypomanic episodes as well as the suicide risk. There is a psychometric validation for each module compared to the Structured Clinical Interview for DSM [SCID $]^{15}$. According to the MINI, an episode of depression is characterized by the presence of a persistent depressed 
mood, a loss of interest, or a decreased pleasure in usual activities, with a minimum duration of two weeks. On the other hand, BD is characterized by the presence of at least one manic episode, an alternating depressive episode or at least one overlapped manic/ hypomanic episode. The manic and hypomanic episodes are characterized by abnormal, persistently high, expansive or irritable moods and increased activity or energy, lasting at least one week. A Mixed episode is considered when the respondent rates both manic and depression episodes simultaneously. Lifetime suicide risk was considered when the individual reports ideation, planning, current or past suicide attempts ${ }^{16}$.

After instruments coding, all data was double-entered into the Epi-Info 6.04d program ${ }^{17}$. STATA 9 software was used for data analysis, in which a univariate analysis was performed to describe the sample distribution and obtain the relative frequency of depression, manic/hypomanic and suicide risk. The chi-square statistic test was applied in the cross data analysis. Finally, in the adjusted analysis prevalence ratio (PR) was obtained by Poisson regression with a robust adjustment of variance and control for the design effect in STATA software. For all hypothesis tests, the level of statistical significance was set at $p<$ 0.05 .

All the subjects of the study signed an informed consent form. The study was approved by the Research Ethics Committee of the Universidade Católica de Pelotas (UCPel).

\section{Results}

In the present study, 1.762 subjects were identified. Among these, $202(11,5 \%)$ individuals refused to participate or could not be located at the time of the interview, resulting in a final sample of 1560 . The average age was $20.5( \pm 2.1)$ years; female sex was prevalent $(56.4 \%)$, with elementary school completed or incomplete high school $(47.9 \%)$. Most household heads had an incomplete elementary school $(42.1 \%)$, came from class C (48.1\%). Most parents were living together $(64.1 \%)$ (Table 1$)$.

Concerning mood disorders, the depressive episode was more prevalent in $10 \%$ of the individuals interviewed, followed by mixed episode $(2.4 \%)$ and by the manic/hypomanic episode $(2.3 \%)$. Suicide risk $(8.6 \%)$ was detected in 134 individuals (Table 1). Of the total sample, $3.1 \%$ $(\mathrm{n}=48)$ participants experienced sexual vio- lence (rape) at some point in their lives. Sexual violence was more prevalent in young women than in young men, $4.1 \%$ and $1.8 \%$, respectively (RP $2.31 ; p=0.013)$; and in those with lower schooling level $(p=0.004)$. It also showed higher prevalence in household heads who had incomplete elementary school $(p=0.062)$ and lower socio-economic status ( $\mathrm{D}$ or E) ( $p=0.053)$. Young individuals whose parents were divorced or separated had a higher prevalence of sexual violence $4.4 \%$ (RP 1.81; $p=0.049$ ) (Table 2).

Among the individuals who suffered sexual violence, the prevalence of depressive episode was $24.4 \%$, (hypo)manic episode was $3.1 \%$, while mixed episode was $13.9 \%$, and the lifetime suicide risk was present in $29.2 \%$ (Figure 1). There

Table 1. Socio-demographic and clinical characteristics among young people of 18 to 24 years old in the city of Pelotas, Brazil.

\begin{tabular}{lr}
\hline \multicolumn{1}{c}{ Sample Characteristics } & \multicolumn{1}{c}{ N (\%) } \\
\hline Sex & \\
Female & $880(56.4)$ \\
Male & $680(43.6)$ \\
Age (Mean \pm SD) & $20.50 \pm 2.09$ \\
Education of young & \\
Incomplete elementary school & $342(27.9)$ \\
Complete elementary school/ & $748(47.9)$ \\
Incomplete high school & \\
Complete high school / higher & $470(30.1)$ \\
Education of the head of the household & \\
Incomplete elementary school & $656(42.1)$ \\
Complete elementary school/ & $314(20.1)$ \\
Incomplete high school & \\
Complete high school/ higher & $590(37.8)$ \\
Socioeconomic status & \\
High (A+B) & $583(37.4)$ \\
Medium (C) & $751(48.1)$ \\
Low (D+E) & $226(14.5)$ \\
Parents' marital status & $1560(100.0)$ \\
Living together & \\
Not living together & $1000(64.1)$ \\
Sexual abuse & $560(35.9)$ \\
No & \\
Yes & $1512(96.9)$ \\
Current mood disorder & $48(3.1)$ \\
Without & \\
Depressive episode & \\
Manic (hypo) episode & \\
Mixed episode & \\
Lifetime suicide risk & \\
No & \\
\hline
\end{tabular}


Table 2. Socio-demographic factors associated with the occurrence of lifetime sexual violence.

\begin{tabular}{|c|c|c|c|}
\hline Characteristic & $\begin{array}{l}\text { Prevalence of sexual } \\
\text { violence } \mathbf{n}(\%)\end{array}$ & $\begin{array}{l}\text { Prevalence ratio } \\
\text { CI }(95 \%)\end{array}$ & $p$-value \\
\hline Sex & & & 0.013 \\
\hline Female & $36(4.1)$ & $2.31(1.21-4.42)$ & \\
\hline Male & $12(1.8)$ & 1.00 & \\
\hline Education of young & & & 0.004 \\
\hline Incomplete elementary school & $17(5.1)$ & $3.41(1.43-8.14)$ & \\
\hline Complete elementary school/ Incomplete high school & $24(3.2)$ & $2.15(0.93-4.95)$ & \\
\hline Complete high school / higher & $7(1.5)$ & 1.00 & \\
\hline Education of the head of the household & & & 0.062 \\
\hline Incomplete elementary school & $28(4.3)$ & $2.09(1.07-4.08)$ & \\
\hline Complete elementary school/ Incomplete high school & $8(2.6)$ & $1.25(0.52-3.02)$ & \\
\hline Complete high school / higher & $12(2.1)$ & 1.00 & \\
\hline Socioeconomic status & & & 0.053 \\
\hline $\operatorname{High}(A+B)$ & $15(2.6)$ & 1.00 & \\
\hline Medium (C) & $20(2.7)$ & $1.04(0.54-2.02)$ & \\
\hline Low $(\mathrm{D}+\mathrm{E})$ & $13(5.8)$ & $2.23(1.08-4.62)$ & \\
\hline Parents' marital status & & & 0.049 \\
\hline Living together & $24(2.4)$ & 1.00 & \\
\hline Not living together & $24(4.4)$ & $1.81(1.04-3.16)$ & \\
\hline Total & $48(3.1)$ & - & - \\
\hline
\end{tabular}

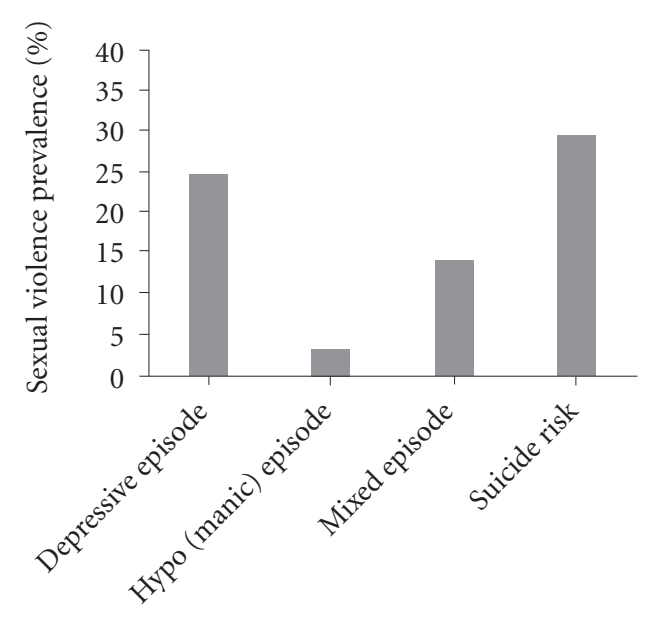

Figure 1. Prevalence of sexual violence among young adults with mood episodes and suicide risk (\%).

were statistically significant differences for all mood episodes and suicide risk $(\mathrm{p}<0.05)$, except for manic episode $(\mathrm{p}>0.05)$ when compared to subjects who had not suffered sexual violence.

In the adjusted analysis, when adjusted for sex, educational level of the individuals and of the head of the household, the socioeconomic status, the families whose parents were separated, the mood episode and the lifetime suicide risk, except (hypo) manic episode, showed higher prevalence among young people who had suffered sexual violence. For those individuals who suffered sexual violence, the probability of having depressive episodes was approximately two times higher when compared to those who did not suffer sexual violence (RP 1.94; CI 95\% 1.10 - 3.41); for mixed episodes, the probability was 4 times higher (RP 3.92; CI 95\% 1.48 - 10.32), while the probability of lifetime suicide risk was 2.8 times higher among individuals who suffered sexual violence (RP 2.83; CI 95\% 1.76-4.54). Sexual violence in this sample has not been associated with the higher prevalence of (hypo) mania episode (RP 1.08; CI 95\% 0.15- 7.84) (Table 3).

\section{Discussion}

The present study has pointed out a strong association between the history of sexual violence and the presence of mood disorders, especially regarding mixed episodes. In addition, the reports of sexual violence were highly associated with the lifetime suicide risk and with some socio-demographic factors. It was observed that $3.1 \%$ of the 
Table 3. Prevalence Ratio of young people who have suffered sexual violence presenting mood disorders and suicide risk.

\begin{tabular}{lcc}
\hline \multicolumn{1}{c}{ Current disorder } & $\begin{array}{c}\text { Young people who suffered sexual violence } \\
\text { Prevalence Ratio (CI 95\%) }\end{array}$ & $\boldsymbol{p}$-value \\
\hline Depressive episode & $1.94(1.10-3.41)$ & 0.021 \\
Manic episode (hypo) & $1.08(0.15-7.84)$ & 0.938 \\
Mixed episode & $3.92(1.48-10.32)$ & 0.006 \\
Suicide risk & $2.83(1.76-4.54)$ & $<0.001$ \\
\hline
\end{tabular}

sample reported that they were forced to have sexual intercourse.

In this study and in the literature, some socio-demographic variables, such as the female sex, low level of schooling, low family income and families whose young's parents are separated are associated with sexual violence ${ }^{18-20}$. Likewise, a series of psychiatric disorders, including mood disorders and suicide risk, are associated with sexual assault ${ }^{7-9,21-24}$.

In the present study, the prevalence of depression among people who suffered sexual violence was nearly three times higher than among those of the population group. Kilpatrick et al. ${ }^{25}$, 1985 , found that $30 \%$ of victims who suffered sexual abuse experienced at least one episode of depression, and yet, 21\% were depressed at the time of evaluation. Data that are assimilated to the present study found that the prevalence of current depression in $24.4 \%$. In a study focused on child sexual abuse and subsequent diseases conducted in the United States, the percentage of women with depression during life was 39.3\% among those women who reported child sexual abuse when compared to a general population with $21.3 \%$. In this study, the sexual abuse had a high prevalence in those young people with the mixed episode (14.3\%). Meade et al., (2009) suggests that women were not only more likely to report sexual abuse, but they also reported significantly more weeks of mixed episodes having an immense impact therefore worsening quality of life in young adults ${ }^{8}$. Neria et al. ${ }^{26}$ evaluated 109 patients with bipolar disorder and found that $40.4 \%$ experienced sexual or physical trauma and it is more prevalent in women than in men.

On the other hand, there were no association between hypo (manic) episode and sexual violence in our study. It is not clear in the literature the mechanism involved between sexual violence and bipolar disorder. Afifi et al., in a population study did not find an association between bipo- lar disorder and sexual abuse, which is similar with our results ${ }^{9}$. However, our study shows that people who suffered sexual violence demonstrated 3.9 chances of presenting a mixed episode. This finding can be explained by the severity of the pathology. It is known in the literature that subjects who present mixed episodes have greater damage in quality of life and global functioning $^{13,27}$. Therefore, the trauma in childhood could aggravate the pathology prognostic or even how the pathology appears.

According to a meta-analysis carried out by Norman et al. (2012), individuals who have suffered sexual assault are three times more likely to present suicidal ideation, when compared to those who did not suffer such abuse ${ }^{28}$. Afifi et al. ${ }^{9}$ observed individuals with the presence of past sexual abuse and the likelihood ratio for suicide ideation was 2.3.This finding is similar to that found in the present study, in which the lifetime suicide was 2.8 times more prevalent. Alvarez et al. ${ }^{29}$ evaluated 102 patients with a diagnosis of schizophrenia, bipolar and schizoaffective disorder and found that the suicide risk was two times more prevalent in those patients who had suffered sexual abuse. In another study, researchers found that adolescents female who suffered sexual assault presented an odds ratios of 3 to develop bipolar disorder ${ }^{2}$.

Sexual assault in childhood or adolescence can be a major stressor event to predict mood disorders and suicide ideation in adult life. It is worth mentioning that factors that characterize the social vulnerability are also involved in this association, which justifies the studies focused on the impact of sexual violence in mood disorders and suicide risk, taking into account the socio-demographic factors associated with the abuse.

One of the limitations of this study is the impossibility to infer causal relationships between sexual violence, the mood episodes and the sui- 
cide risk. It is not possible to say that sexual violence is the cause and clinical conditions are the consequences. However, these findings were obtained from a population-based cross-sectional design with young adults who, in their great majority, were not receiving any psychological or psychiatric support for mood disorders. Moreover, the study demonstrated that the relation- ship between sexual violence and mood disorders may result in damage and suffering already in a sample of young adults. Further population-based longitudinal studies are necessary not only to identify the actual effects of sexual violence on the lives of young adults, but also to better understand the neurobiological consequences that those traumatic experiences may bring.

\section{Collaborations}

TC Mondin, TA Cardoso, K Jansen, CE Konradt, RF Zaltron, MO Behenck, LD Mattos and RA Silva contributed intellectually to the article; TC Mondin, TA Cardoso, K Jansen and CE Konradt analyzed the data; TC Mondin, TA Cardoso, K Jansen, CE Konradt, RF Zaltron and MO Behenck wrote the article; TC Mondin, TA Cardoso, K Jansen, LD Mattos and RA Silva were responsible for the final content of the article. All authors read and approved the final version of the article.

\section{Acknowledgements}

The authors gratefully acknowledge the financial support provided by the Fundação de Amparo à Pesquisa do Estado do Rio Grande do Sul (FAPERGS) and the Conselho Nacional de Desenvolvimento Científico e Tecnológico (CNPq). 


\section{References}

1. Gal G, Levav I, Gross R. Psychopathology among adults abused during childhood or adolescence: results from the Israel-based World Mental Health Survey. J Nerv Ment Dis 2011; 199(4):222-229.

2. Rees S, Silove D, Chey T, Ivancic L, Steel Z, Creamer M, Teesson M, Bryant R, McFarlane AC, Mills KL, Slade T, Carragher N, O’Donnell M, Forbes D. Lifetime prevalence of gender-based violence in women and the relationship with mental disorders and psychosocial function. JAMA 2011; 306(5):513-521.

3. Sachs-Ericsson N, Kendall-Tackett KA, Sheffler J, Arce D, Rushing NC, Corsentino E. The influence of prior rape on the psychological and physical health functioning of older adults. Aging Ment Health 2014; 18(6):717730 .

4. Spataro J, Mullen PE, Burgess PM, Wells DL, Moss SA. Impact of child sexual abuse on mental health: Prospective study in males and females. Br J Psychiatry 2004; 184(5):416-421.

5. Turner HA, Finkelhor D, Ormrod R. The effect of lifetime victimization on the mental health of children and adolescents. Soc Sci Med 2006; 62(1):13-27.

6. Krug E, Dahlberg L, Mercy J, Zwi A, Lozano R.World report on violence and health. 2009. [cited 2014 jan 2]. Available from: http://www.who.int/violence_injury_prevention/violence/world_report/e/

7. Erten E, Funda Uney A, Saatçio lu Ö, Özdemir A, Fıstıkçı N, Çakmak D. Effects of childhood trauma and clinical features on determining quality of life in patients with bipolar I disorder. J Affect Disord 2014; 162:107-113.

8. Meade CS, McDonald LJ, Graff FS, Fitzmaurice GM Griffin ML, Weiss RD. A prospective study examining the effects of gender and sexual/physical abuse on mood outcomes in patients with co-occurring bipolar I and substance use disorders. Bipolar Disord 2009; 11(4):425-433.

9. Afifi TO, MacMillan HL, Boyle M, Taillieu T, Cheung $\mathrm{K}$, Sareen J. Child abuse and mental disorders in Canada. J Can Acad Child Adolesc Psychiatry 2014; 186(9):E324-E332.

10. Creighton CD, Jones AC. Psychological profiles of adult sexual assault victims. J Forensic Leg Med 2012; 19(1):35-39.

11. Maniglio R. The impact of child sexual abuse on the course of bipolar disorder: a systematic review. Bipolar Disord 2013; 15(4):341-358.

12. Lurie S, Boaz M, Golan A. Risk factors for rape re-victimisation: A retrospective analysis. J Obstet Gynaecol 2013; 33(8):865-867.

13. Jansen K, Campos Mondin T, Azevedo Cardoso T, Costa Ores L, Mattos Souza LD, Tavares Pinheiro R, Silva Magalhães PV, Silva RA. Quality of life and mood disorder episodes: Community sample. J Affect Disord 2013; 147(1):123-127.

14. Associação Brasileira de Ensino e Pesquisa (ABEP). Critério de classificação econômica Brasil. 2008. [cited 2014 jan 2]. Available from: http://www.abep.org/codigosguias/criterio_brasil_2008.pdf
15. Amorim P. Mini International Neuropsychiatric Interview (MINI): validação de entrevista breve para diagnóstico de transtornos mentais. Rev Bras Psiquiatr 2000; 22(3):106-115.

16. American Psychiatric Association. Diagnostic and Statistical Manual for Mental Disorders. $4^{\text {th }}$ ed. Washington: American Psychiatric Press; 1994.

17. Dean AG, Brendel KA, Smith DC, Burton AH, Dicker RC, Sullivan K, Fagan RF, Arner TG. Epi-Info version 6.04d. A word processing database, and statistics program for epidemiology on microcomputers. Atlanta: Center of disease control and prevention; 1994.

18. Gault-Sherman M, Silver E, Sigfúsdottir ID. Gender and the associated impairments of childhood sexual abuse: A national study of Icelandic youth. Soc Sci Med 2009; 69(10):1515-1522.

19. Butchart A, Phinney Harvey A, Kahane T, Mian MTF Preventing child maltreatment: a guide to action and generating evidence. Geneva: World Health Organization, International Society for Prevention of Child Abuse and Neglect; 2006.

20. Romero S, Birmaher B, Axelson D, Goldstein T, Goldstein BI, Gill MK, Iosif AM, Strober MA, Hunt J, Esposito-Smythers C, Ryan ND, Leonard H, Keller M. Prevalence and correlates of physical and sexual abuse in children and adolescents with bipolar disorder. J Affect Disord 2009; 112(1-3):144-150.

21. Behnken MP, Le YC, Temple JR, Berenson AB. Forced sexual intercourse, suicidality, and binge drinking among adolescent girls. Addict Behav 2010; 35(5):507509.

22. Conus P, Cotton S, Schimmelmann BG, Berk M, Daglas $\mathrm{R}$, McGorry PD, Lambert M. Pretreatment and outcome correlates of past sexual and physical trauma in 118 bipolar I disorder patients with a first episode of psychotic mania. Bipolar Disord 2010; 12(3):244-252.

23. Pillai A, Andrews T, Patel V. Violence, psychological distress and the risk of suicidal behaviour in young people in India. Int J Epidemiol 2009; 38(2):459-469.

24. Tiet QQ, Finney JW, Moos RH. Recent sexual abuse, physical abuse, and suicide attempts among male veterans seeking psychiatric treatment. Psychiatr Serv 2006; 57(1):107-113.

25. Kilpatrick DG, Veronen LJ, Best CL. Factors predicting psychological distress among rape victims. New York: Brunner; 1985.

26. Neria Y, Bromet EJ, Carlson GA, Naz B. Assaultive trauma and illness course in psychotic bipolar disorder: findings from the suffolk county mental health project. Acta Psychiatr Scand 2005; 111(5):380-383.

27. Jansen K, Magalhães PVS, Tavares RP, Kapczinski F, Silva RA. Early functional impairment in bipolar youth: A nested population-based case-control study. J Affect Disord 2011; 142(1-3):208-212.

28. Norman RE, Byambaa M, De R, Butchart A, Scott J, Vos T. The Long-Term Health Consequences of Child Physical Abuse, Emotional Abuse, and Neglect: A Systematic Review and Meta-Analysis. PLoS Med 2012; 9(11):e1001349. 
29. Alvarez MJ1, Roura P, Osés A, Foguet Q, Solà J, Arrufat FX. Prevalence and clinical impact of childhood trauma in patients with severe mental disorders. J Nerv Ment Dis 2011; 199(3):156-161.

Artigo apresentado em 17/03/2015

Aprovado em 07/07/2015

Versão final apresentada em 09/07/2015 